Katharina Glatz-Krieger · Mona Pache • Coya Tapia • Alain Fuchs • Spasenija Savic • Dieter Glatz •

Michael Mihatsch • Peter Meyer

\title{
Anatomic site-specific patterns of gene copy number gains in skin, mucosal, and uveal melanomas detected by fluorescence in situ hybridization
}

Received: 21 December 2005 / Accepted: 25 January 2006 / Published online: 8 March 2006

C) Springer-Verlag 2006

\begin{abstract}
To assess the differences between melanomas of different location and different etiology, 372 malignant melanomas were brought in a tissue microarray format. The collection included 23 acral and 118 non-acral skin melanomas, 9 mucosal melanomas, 100 uveal melanomas, and 122 melanoma metastases. Fluorescence in situ hybridization (FISH) was used to assess copy number changes of the cyclin D1 (CCND1), MDM2, c-myc (MYC), and HER2 genes. FISH analysis revealed distinct differences between melanomas from different locations. CCND1 amplifications were detected in skin melanomas from sites with chronic sun exposure (6 of 32 cases), acral melanomas (4 of 17 cases), and mucosal melanomas (one of ten cases) but not in uveal melanomas. High-level MDM2 amplifications were exclusively present in acral melanomas ( 2 of 19 cases). MYC copy number gains were detected in 32 of 71 uveal melanomas, five of eight mucosal melanomas, and 6 of 67 melanomas from sites with intermittent sun exposure but not in acral melanomas nor melanomas from sites with chronic sun exposure. Alterations of the MYC gene were associated with advanced tumor stage. There were no high-level HER2 amplifications. Site-specific genetic and epigenetic features may impact the response of melanomas to various anticancer drugs and should be considered in future studies on the molecular pathogenesis of malignant melanomas.
\end{abstract}

\footnotetext{
K. Glatz-Krieger $(\bowtie) \cdot$ C. Tapia · A. Fuchs $\cdot$ S. Savic .

M. Mihatsch - P. Meyer

Institute for Pathology, University of Basel,

Schoenbeinstrasse 40,

CH-4031 Basel, Switzerland

e-mail: Katharina.Glatz@unibas.ch

Tel.: +41-61-2652880

Fax: +41-61-2653194

M. Pache $\cdot$ P. Meyer

University Eye Clinic of Basel,

Basel, Switzerland

D. Glatz

IT Department, University of Basel,

Basel, Switzerland
}

Keywords Melanoma - Fluorescence in situ hybridization · Tissue array · Amplification

\section{Introduction}

There is considerable hope that a new generation of anticancer drugs targeting specific genes or molecular pathways may be more efficient in the future. The introduction of trastuzumab (Herceptin), a humanized antibody for the treatment of HER2-positive metastatic breast cancer [9, 29], has pointed out the potential of molecular-targeted therapy. As the results of systemic treatment with classical cytostatic drugs in melanoma patients presenting distant metastases have been discouraging with only a minority of these patients living beyond 1 year [1]. The discovery of frequent mutations of the BRAF gene in malignant melanomas [13] and the subsequent development of BRAF antagonists [7] have raised new hope. If individual molecular features should be targeted in cancer cells, melanoma subgroups with different molecular signatures may be clinically important. It is interesting that there is increasing evidence for distinct molecular characteristics of melanoma subtypes depending on the localization and different levels of sun exposure of the primary tumor $[3,5$, $11,12,33,37,39,42]$. It is tempting to speculate that such differences may be due to a site-specific etiology of melanoma. For example, mutations of the BRAF gene have been shown to be preferentially present in melanomas from sites with intermittent sun exposure $[12,24]$ and acral melanomas [33] but were nearly inexistent in tumors arising in sites of chronic sun-induced damage, mucosal melanomas [15], and uveal melanomas [10, 14]. Gene amplifications were found to be significantly more frequent in acral and mucosal melanomas than in melanomas from non-acral skin $[3,12]$. In addition to the site-specific differences in the degree of genomic instability, there is increasing evidence of distinct patterns of genetic alterations depending on the localization of the primary tumor $[12,41]$. 
To collect more information on possible site-specific molecular differences, we determined the frequency of amplifications of the proto-oncogenes cyclin D1 (CCND1), MDM2, c-myc (MYC), and HER2 in melanomas from different localizations including mucosal and uveal melanomas. For the purpose of this study, we selected a tissue microarray format which allowed us to analyze a total of 372 melanomas on one tissue slide under highly standardized experimental conditions.

\section{Materials and methods}

\section{Tumors}

Formalin-fixed and paraffin-embedded tissues from 141 primary skin melanomas, 100 uveal melanomas, 9 mucosal melanomas, and 122 metastases (70 lymph node and 52 hematogenous) were brought in a tissue microarray (TMA) format [21]. Primary tumors and corresponding metastases were available from 16 patients and more than one metastasis from 12 patients. Among the 141 primary skin melanomas, there were 37 melanomas located in areas of chronic sun exposure (27 in the head/neck and 10 in the forearm), 78 melanomas located in areas of intermittent sun exposure (45 in the thorax, 8 in the upper arm, and 25 in the legs), 2 anal melanomas (no sun exposure), 23 acral melanomas, and 1 melanoma of unknown location. All melanomas from sites with chronic sun exposure (head/ neck and forearm) had marked solar elastosis microscopically. All cases were classified according to the pTNM classification (UJCC, 6th edition, 2003). The stages of skin and primary mucosal tumors were pTis in $6, \mathrm{pT} 1 \mathrm{a}$ in 32 , pT1b in 3, pT2a in 27, pT2b in 4, pT3a in 23, pT3b in 14, pT4a in 12 , and pT4b in 29 . The subtypes of the primary tumors were as follows: superficial spreading (82), nodular (46), lentigo maligna (5), and acral lentiginous (17). The pT stages of the uveal melanomas were pT1a in 3, pT1b in 1 , pT2a in $25, \mathrm{pT} 2 \mathrm{~b}$ in $27, \mathrm{pT} 2 \mathrm{c}$ in $6, \mathrm{pT} 3$ in 15 , and pT4 in 20. pT stage could not be determined in three uveal melanomas. Histologically, a spindle-cell type was present in 50, an epitheloid type in 13, and a mixed type in 37 cases of uveal melanomas. All slides from all tumors were reviewed by one of two pathologists (K.G. for non-uveal melanomas and P.M. for uveal melanomas) to define the histological tumor type and the pathological stage.

A semiautomated arraying instrument was used for TMA construction as described [36]. A representative tissue cylinder of the vertical growth phase was taken for the tissue array from primary tumors in the vertical growth phase (119) and of the radial growth phase from primary tumors in the radial growth phase (22). Of the 25 skin melanomas and 40 uveal melanomas, two tissue cores from the same tumor block were placed in the tissue array.

Tissue samples were collected during 1985-2002 at our institution. The use of the archival material and data in research was approved by the Ethics Committee of the University Hospital Basel.
Fluorescence in situ hybridization

A set of 4- $\mu \mathrm{m}$ TMA sections was used for two-color fluorescence in situ hybridization (FISH). For the proteolytic slide pretreatment, a commercial kit was utilized (Paraffin pretreatment reagent kit, Vysis, Downers Grove, IL, USA). Spectrum Orange-labeled CCND1, MDM2, MYC, and HER2 were used in combination with Spectrum Green-labeled chromosomes 11, 12, 8, and 17 centromeric probes as a reference. All locus-specific probes were obtained from Vysis, IL, USA. Before hybridization, the sections were deparaffinized, air dried, and dehydrated in 70,85 , and $100 \%$ ethanol followed by denaturation for $5 \mathrm{~min}$ at $74^{\circ} \mathrm{C}$ in $70 \%$ formamide $-2 \times \mathrm{SSC}$ solution. After overnight hybridization at $37^{\circ} \mathrm{C}$ in a humidified chamber, slides were washed and counterstained with $0.2 \mu \mathrm{M}$ DAPI in an anti-fade solution. For each tumor, the predominant gene and centromere copy numbers were estimated. A tumor was considered amplified if the ratio of gene probe to centromere probe was $\geq 2.0$.

\section{Statistical analysis}

Contingency table analysis and chi-square tests were used to study frequency comparisons of nominal categorized variables.

\section{Results}

FISH analysis was successful for CCND1 in 293 (79\%), for MDM2 in 301 (81\%), for MYC in $271(73 \%)$, and HER2 in $322(87 \%)$ out of the 372 melanoma samples. Noninformative samples were mainly caused by insufficient hybridization, too high background, or absence of tumor cells on arrayed tissues.

\section{CCND1}

CCND1 amplifications were found in $8 \%$ of 120 primary skin and mucosal melanomas and in $11.2 \%$ of 107 metastases from skin melanomas but in none of the 83 uveal melanomas. Among the 21 amplified cases, there were eight tumors with high-level amplifications showing $>10$ CCND1 signals per tumor cell (Fig. 1). The associations with localization, metastases, and stage are shown in Table 1. It ia interesting that CCND1 amplification was significantly more frequent in acral melanomas and melanomas of the forearm and the head and neck (chronic sun exposure) than in melanomas of the trunk, the legs, and the upper arms (intermittent sun exposure, $p=0.001$ ). All melanomas from chronically sun-exposed sites with CCND1 amplifications showed moderate to severe solar elastosis. As lentigo maligna melanomas arise in chronically sun-damaged skin, CCND1 amplifications were more frequent in this subtype than in superficial spreading or nodular melanomas. 
MYC

An increase of MYC gene copies was frequently observed in uveal $(45.1 \%$ of 71$)$ and mucosal $(62.5 \%$ of 8$)$ melanomas but only rarely in melanomas from sites with intermittent sun exposure (9\% of 67) and not from sites with chronic sun exposure or acral sites. In most cases with increased MYC signals, there were only low-level MYC gene copy number gains with the ratio of MYC copies as compared to centromere 8 being 2:1. Clear-cut high-level MYC amplifications with an average ratio of MYC signals per centromere 8 above 5 and the signals occurring in distinct clusters was found in four tumor samples: a nodular melanoma of the upper arm, a nodular melanoma of the elbow, an esophageal melanoma, and a subcutaneous metastasis of a substernal primary. The esophageal melanoma was the only tumor in this study showing high-level amplifications of two genes (CCND1 in addition to MYC).

There was an association between MYC copy number increase and increased tumor stage when all stages were compared $(p=0.018)$. MYC alterations were significantly more frequent in melanomas from the nodular than the superficial spreading type $(p=0.002)$.

\section{MDM2}

MDM2 amplifications were found in 3.6\% of 139 primary tumors of the skin but not in metastases nor uveal melanomas. Two of five amplified tumors had high-level amplifications (>10 MDM2 copies per cell, Fig. 1). Both were acral melanomas (Table 1).

\section{HER2}

One primary tumor from the back skin (Breslow $0.98 \mathrm{~mm}$, pT2) showed a low-level amplification of the HER2 gene (two centromere and five HER2 copies per cell). All the

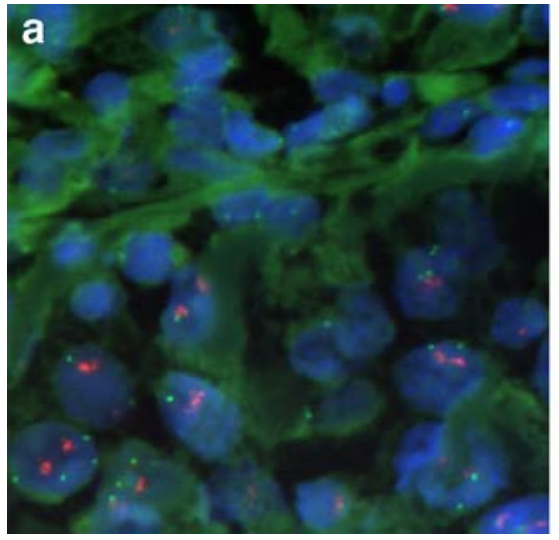

Fig. 1 a CCND1 amplification in a lentigo maligna melanoma. Hybridization was done with probes for centromere 11 (green) and CCND1 (red). Large tumor cells in the lower half of the image contain one or two irregularly formed clusters consisting of many closely packed red CCND1 signals and up to four centromere 11 other 322 interpretable primary melanomas and metastases showed no HER2 amplifications.

\section{Results of multiple samples from one patient}

For CCND1, MDM2, and HER2, all multiple samples from the same patient showed a consistent result. Among these multiple samples, there were four concordant amplifications of the CCND1 gene [multiple metastases $(2 \times)$, samples of the same tumor block $(1 \times)$, and a primary tumor of the esophagus with its lymph node metastasis].

The evaluation of the MYC gene revealed some discrepant results in multiple samples of the same patient. In five uveal melanomas and one skin melanoma, one tissue cylinder had low-level MYC gene copy number gains while the other cylinder of the same tumor block showed a normal MYC copy number as a result of intratumoral heterogeneity. The primary tumor of an esophageal melanoma but not its corresponding lymph node metastasis had a high-level MYC amplification. In another 45 cases with multiple tissue cylinders from one patient, the results of MYC copy numbers of all samples were congruent. Of these 45 cases, 24 had an increased MYC copy number.

\section{Discussion}

In this study, the analysis of 372 melanoma tissue samples revealed significant molecular differences between tumors of different sites.

FISH was used to investigate gene amplifications of CCND1, MDM2, MYC, and HER-2. Among these genes, high-level amplifications of CCND1 were most frequent. It is interesting that CCND1 amplification was significantly more frequent in locations with chronic sun exposure (head/neck and forearms) than in locations with intermittent sun exposure (trunk, legs, and upper arms), raising the

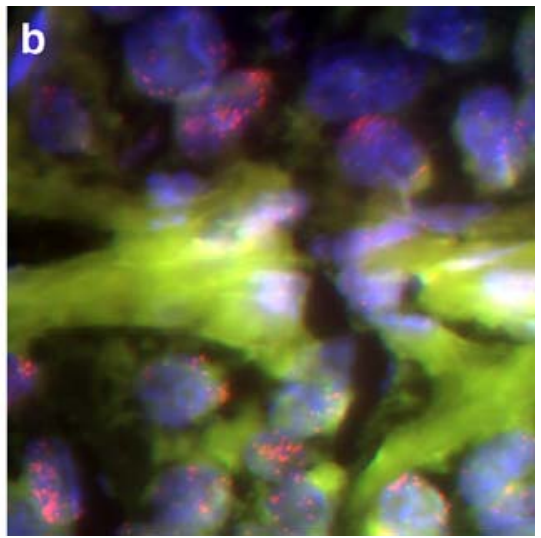

signals. $\times 640$ magnification. b MDM2 high-level amplification in acral lentiginous melanoma. Hybridization was done with probes for centromere12 (green) and MDM2 (red). Large tumor cells with several clusters of MDM2 signals. $\times 640$ magnification 
Table 1 Molecular findings, tumor phenotype, stage, and location

\begin{tabular}{|c|c|c|c|c|c|}
\hline & & CCND1 (\%) & MDM2 (\%) & MYC (\%) & HER2 (\%) \\
\hline \multirow[t]{5}{*}{ Localization of primary tumor } & Uvea & $0 / 83$ & $0 / 59$ & $32 / 71(45.1)$ & $0 / 78$ \\
\hline & Intermittent sun exposure & $0 / 65$ & $3 / 72(4.8)$ & $6 / 67(9)$ & $1 / 66(1.5)$ \\
\hline & Chronic sun exposure & $6 / 32(18.8)^{\mathrm{a}}$ & $0 / 32$ & $0 / 24$ & $0 / 33$ \\
\hline & Acral & $4 / 17(23.5)^{b}$ & $2 / 19(10.5)$ & $0 / 9$ & $0 / 19$ \\
\hline & Mucosa & $1 / 10(10)$ & $0 / 8$ & $5 / 8(62.5)$ & $0 / 9$ \\
\hline \multirow[t]{4}{*}{ pT (skin primary tumors) } & pT1 & $1 / 24(4.2)$ & $3 / 27(11.1)$ & $0 / 25$ & $1 / 21(4.8)$ \\
\hline & pT2 & $2 / 25(8.0)$ & $0 / 26$ & $1 / 25(4)$ & $0 / 28$ \\
\hline & pT3 & $3 / 32(9.4)$ & $1 / 34(2.9)$ & $4 / 29(13.8)$ & $0 / 33$ \\
\hline & pT4 & $5 / 33(15.2)$ & $1 / 32(3.1)$ & $6 / 23(26.1)^{\mathrm{c}}$ & $0 / 34$ \\
\hline \multirow[t]{2}{*}{ Metastases } & Lymph node & $8 / 65(12.3)$ & $0 / 60$ & $3 / 92$ & $0 / 66$ \\
\hline & Distant & $5 / 43(11.6)^{\mathrm{d}}$ & $0 / 46$ & $3 / 92$ & $0 / 43$ \\
\hline \multirow[t]{2}{*}{ Growth phase } & Radial & $0 / 18$ & $1 / 17(5.9)$ & $0 / 17$ & $0 / 21$ \\
\hline & Vertical & 11/101 (10.9) & 4/107 (3.7) & 7/92 (12.0) & $1 / 102(1.0)$ \\
\hline \multirow[t]{4}{*}{ Histologic subtype } & Superficial spreading & $3 / 70(4.3)$ & $3 / 71(4.2)$ & $2 / 67(6.0)$ & $1 / 71(1.4)$ \\
\hline & Nodular & $3 / 39(7.7)$ & $0 / 37$ & $7 / 31(22.6)^{\mathrm{e}}$ & $0 / 38$ \\
\hline & Lentigo maligna & $2 / 4(50)$ & $0 / 5$ & $0 / 3$ & $0 / 5$ \\
\hline & Acral lentiginous & $3 / 12(25)$ & 2/13 (15.4) & $0 / 8$ & $0 / 14$ \\
\hline
\end{tabular}

Tumors with CCND1, MDM2, MYC, and HER2 gene probe to centromere probe ratio $\geq 2.0$ detected by FISH. Percentages are indicated in brackets

${ }^{\text {a }}$ Site of chronic sun exposure (head/neck and forearm) vs site of intermittent sun exposure (upper arm, leg, and trunk), $p<0.0001$

${ }^{\mathrm{b}}$ Acral vs non-acral skin, $p=0.02$

${ }^{\mathrm{c}} \mathrm{MYC}$ copy number increases when all stages are compared, $p=0.018$

${ }^{\mathrm{d}}$ Primary tumors vs metastases, $p<0.0001$

'Nodular vs superficial spreading type, $p=0.002$

possibility that CCND1 activation could be particularly important for melanoma development in sites with chronic sun exposure. Our overall frequency and site distribution of CCND1 amplifications in primary skin melanomas is consistent with previous data $[12,34]$.

The presence of frequent CCND1 amplifications in acral melanomas could be explained by an overall higher level of genetic instability of these tumors involving other molecular pathways than in classical skin melanoma $[5,12]$.

Our mucosal melanoma with CCND1 amplification had originated from the esophagus where CCND1 amplification occurs at a particularly high frequency in carcinomas as well [35]. A review of our case confirmed the melanoma diagnosis, however. In the same tumor, we additionally detected a high-level MYC amplification illustrating the higher degree of genetic instability in mucosal melanomas [12].

MDM2 was only amplified in five melanomas including two high-level amplifications. Both high-level amplifications were seen in acral melanomas. This finding and the overall low number of MDM2 amplifications are consistent with previous data from Bastian et al. [3]. They found 12 q14 copy number gains in 5 of 22 acral melanomas but none in 108 non-acral skin melanomas using CGH and MDM2 amplifications in 1 of 15 acral melanomas by FISH.

Amplifications in acral melanomas but not in non-acral melanomas have been shown to be present in the in situ portion and in the invasive areas at mostly similar levels $[2$, $3]$. It was concluded that the amplifications arise very early during tumor progression in acral melanomas, suggesting that acral melanomas develop a specific amplificationpermissive defect early in tumorigenesis unique to the pathogenesis of this tumor type $[3,5]$. In most cancers, gene amplifications occur frequently at a late stage and are clearly associated with tumor progression though the mechanisms through which amplifications are generated are largely unknown [23]. The fact that amplifications, in general, occur late in tumorigenesis may explain why amplifications are rather frequent in mucosal melanomas [12] which are usually diagnosed at a late stage.

The unique molecular features in uveal melanomas are not unexpected due to their special location. The chromosomes $1,3,6$, and 8 are consistently affected by nonrandom aberrations mainly in the form of chromosomal gains and losses [18, 38]. Additional copies of the long arm of chromosome 8 either by translocation or in the form of an isochromosome $\mathrm{i}(8 \mathrm{q})$ have been shown to correlate with reduced survival [25]. Parrella et al. [27] had described MYC amplification in 14 of 43 uveal melanomas. These amplifications were of borderline nature typically showing twice as many MYC copies as compared to centromere 8 in FISH analysis. Twice as many gene copies as centromere copies typically reflect a duplication of a large stretch of DNA (e.g., isochromosome formation) rather than a genespecific amplification event as has been shown in studies of uveal and skin [22, 39] melanomas. By CGH analysis, over-representation of the long arm of chromosome 8 has been reported in $38 \%$ of primary melanomas [4]. The poor prognosis associated with extra copies of chromosome $8 \mathrm{q}$ may point to the presence of several oncogenes in this region. Ehlers et al. [16] suggest that the DDEF1 gene 
located at $8 \mathrm{q} 24$ rather than MYC which is also located at 8 q24 may function as an oncogene during uveal melanoma progression. The fact that the copy number alterations of the MYC gene are more common in advanced tumors of the nodular subtype has been shown before in studies with limited case numbers $[22,40]$. Blocking the expression of MYC with liposomal MYC antisense oligodeoxynucleotides has been reported to inhibit tumor growth and metastases in an in vivo melanoma model [28]. Hopefully, such an approach will finally provide a targeted therapy for selected patients with advanced melanomas.

One skin melanoma showed HER2 amplification according to our definition. This case had two centromere and five HER2 signals which do not constitute a classical amplification. Persons et al. [30] have also reported one HER2 amplification in 40 advanced melanomas. It is not surprising that several studies have proposed HER2 overexpression in up to $80 \%$ of melanomas $[6,26]$ as IHC can yield highly variable results under non-standardized conditions. More recent IHC studies using Food and Drud Administration-approved reagents have described inexistent [17] or a very low rate of detectable HER2 expression (0.9-3\%) [19, 31] (own unpublished findings). Altogether, these data strongly argue against a possible therapeutic application of Herceptin in malignant melanoma.

The hypothesis of distinct genetic alterations between melanomas arising in different sites is also supported by the results of recent studies on the frequency of BRAF mutations. BRAF mutations have been observed preferentially in melanomas from skin without chronic sun-induced damage [12] but only rarely or not at all in acral melanomas, melanomas from chronically sun-exposed skin, and mucosal and uveal melanomas [10, 15, 24, 33]. The comparison of aberration frequencies in CGH analysis of melanomas with different sun exposure patterns revealed significant differences between the subgroups defined by location [12,34]. Altogether, there is increasing evidence for site-specific molecular pathways of melanoma development.

As we know from H\&E morphology, malignant melanomas often show considerable intratumoral heterogeneity. On several occasions, this heterogeneity has also been observed at the molecular level $[4,8,32]$. TMAs provide a method for the rapid and simultaneous analysis of up to 1,000 tissue samples in a single experiment under highly standardized conditions. They are not intended for making clinical diagnoses of individual cases but to screen for molecular alterations. The validity of TMA analysis has been shown by comparisons with whole-section analysis in breast, prostate, and brain cancer [20].

In a limited number of cases, we had analyzed more than one sample from the same patient revealing a low number of discordant results. It is interesting that, in one case, a high-level MYC amplification was present in the esophageal primary tumor but not in its lymph node metastasis. A more detailed study of intratumoral heterogeneity will be especially important for the evaluation of potential therapeutic targets that should be present throughout the whole tumor and in its metastases if targeted therapy is to be effective. For that purpose, whole-section slides or several samples of different areas within a given tumor, e.g., of the vertical and radial growth phases, will have to be analyzed.

Due to their genetic characteristics, melanomas may respond differently to various cytotoxic and biologic cancer therapies depending on their body location and the presence or absence of chronic sun-induced damage. The latter can roughly be estimated microscopically by the degree of solar elastosis. In future studies that investigate the molecular pathogenesis of malignant melanomas and in clinical trials with new drug targets, the genetic diversity of melanomas from different sites should be taken into account.

Acknowledgements Katharina Glatz-Krieger and Coya Tapia had been supported by a grant from the "Schweizerische Nationalfonds" and the "SAKK", respectively.

\section{References}

1. Balch CM, Soong SJ, Gershenwald JE, Thompson JF, Reintgen DS, Cascinelli N, Urist M, McMasters KM, Ross MI, Kirkwood JM, Atkins MB, Thompson JA, Coit DG, Byrd D, Desmond R, Zhang Y, Liu PY, Lyman GH, Morabito A (2001) Prognostic factors analysis of 17,600 melanoma patients: validation of the American Joint Committee on Cancer melanoma staging system. J Clin Oncol 19:3622-3634

2. Bastian BC (2003) Understanding the progression of melanocytic neoplasia using genomic analysis: from fields to cancer. Oncogene 22:3081-3086

3. Bastian BC, Kashani-Sabet M, Hamm H, Godfrey T, Moore DH 2nd, Brocker EB, LeBoit PE, Pinkel D (2000) Gene amplifications characterize acral melanoma and permit the detection of occult tumor cells in the surrounding skin. Cancer Res 60:1968-1973

4. Bastian BC, LeBoit PE, Hamm H, Brocker EB, Pinkel D (1998) Chromosomal gains and losses in primary cutaneous melanomas detected by comparative genomic hybridization. Cancer Res 58:2170-2175

5. Bastian BC, Olshen AB, LeBoit PE, Pinkel D (2003) Classifying melanocytic tumors based on DNA copy number changes. Am J Pathol 163:1765-1770

6. Bodey B, Bodey Jr B, Groger AM, Luck JV, Siegel SE, Taylor CR, Kaiser HE (1997) Clinical and prognostic significance of the expression of the c-erbB-2 and c-erbB-3 oncoproteins in primary and metastatic malignant melanomas and breast carcinomas. Anticancer Res 17:1319-1330

7. Bollag G, Freeman S, Lyons JF, Post LE (2003) Raf pathway inhibitors in oncology. Curr Opin Investig Drugs 4:1436-1441

8. Casorzo L, Luzzi C, Nardacchione A, Picciotto F, Pisacane A, Risio M (2005) Fluorescence in situ hybridization (FISH) evaluation of chromosomes $6,7,9$ and 10 throughout human melanocytic tumorigenesis. Melanoma Res 15:155-160

9. Cobleigh MA, Vogel CL, Tripathy D, Robert NJ, Scholl S, Fehrenbacher L, Wolter JM, Paton V, Shak S, Lieberman G, Slamon DJ (1999) Multinational study of the efficacy and safety of humanized anti-HER2 monoclonal antibody in women who have HER2-overexpressing metastatic breast cancer that has progressed after chemotherapy for metastatic disease. J Clin Oncol 17:2639-2648

10. Cohen Y, Goldenberg-Cohen N, Parrella P, Chowers I, Merbs SL, Pe'er J, Sidransky D (2003) Lack of BRAF mutation in primary uveal melanoma. Invest Ophthalmol Vis Sci 44: 2876-2878 
11. Cree IA (2000) Cell cycle and melanoma-two different tumours from the same cell type. J Pathol 191:112-114

12. Curtin JA, Fridlyand J, Kageshita T, Patel HN, Busam KJ, Kutzner H, Cho KH, Aiba S, Brocker EB, LeBoit PE, Pinkel D, Bastian BC (2005) Distinct sets of genetic alterations in melanoma. N Engl J Med 353:2135-2147

13. Davies H, Bignell GR, Cox C, Stephens P, Edkins S, Clegg S, Teague J, Woffendin H, Garnett MJ, Bottomley W, Davis N, Dicks E, Ewing R, Floyd Y, Gray K, Hall S, Hawes R, Hughes J, Kosmidou V, Menzies A, Mould C, Parker A, Stevens C, Watt S, Hooper S, Wilson R, Jayatilake H, Gusterson BA, Cooper C, Shipley J, Hargrave D, Pritchard-Jones K, Maitland N, Chenevix-Trench G, Riggins GJ, Bigner DD, Palmieri G, Cossu A, Flanagan A, Nicholson A, Ho JW, Leung SY, Yuen ST, Weber BL, Seigler HF, Darrow TL, Paterson H, Marais R, Marshall CJ, Wooster R, Stratton MR, Futreal PA (2002) Mutations of the BRAF gene in human cancer. Nature 417:949-954

14. Edmunds SC, Cree IA, Di Nicolantonio F, Hungerford JL, Hurren JS, Kelsell DP (2003) Absence of BRAF gene mutations in uveal melanomas in contrast to cutaneous melanomas. Br J Cancer 88:1403-1405

15. Edwards RH, Ward MR, Wu H, Medina CA, Brose MS, Volpe P, Nussen-Lee S, Haupt HM, Martin AM, Herlyn M, Lessin SR, Weber BL (2004) Absence of BRAF mutations in UVprotected mucosal melanomas. J Med Genet 41:270-272

16. Ehlers JP, Worley L, Onken MD, Harbour JW (2005) DDEF1 is located in an amplified region of chromosome $8 \mathrm{q}$ and is overexpressed in uveal melanoma. Clin Cancer Res 11: 3609-3613

17. Fink-Puches R, Pilarski P, Schmidbauer U, Kerl H, Soyer HP (2001) No evidence for c-erbB-2 overexpression in cutaneous melanoma. Anticancer Res 21:2793-2795

18. Hausler T, Stang A, Anastassiou G, Jockel KH, Mrzyk S, Horsthemke B, Lohmann DR, Zeschnigk M (2005) Loss of heterozygosity of $1 p$ in uveal melanomas with monosomy 3 . Int J Cancer 116:909-913

19. Inman JL, Kute T, White W, Pettenati M, Levine EA (2003) Absence of HER2 overexpression in metastatic malignant melanoma. J Surg Oncol 84:82-88

20. Kallioniemi OP, Wagner U, Kononen J, Sauter G (2001) Tissue microarray technology for high-throughput molecular profiling of cancer. Hum Mol Genet 10:657-662

21. Kononen J, Bubendorf L, Kallioniemi A, Barlund M, Schraml P, Leighton S, Torhorst J, Mihatsch MJ, Sauter G, Kallioniemi OP (1998) Tissue microarrays for high-throughput molecular profiling of tumor specimens. Nat Med 4:844-847

22. Kraehn GM, Utikal J, Udart M, Greulich KM, Bezold G, Kaskel P, Leiter U, Peter RU (2001) Extra c-myc oncogene copies in high risk cutaneous malignant melanoma and melanoma metastases. Br J Cancer 84:72-79

23. Lengauer C, Kinzler KW, Vogelstein B (1998) Genetic instabilities in human cancers. Nature 396:643-649

24. Maldonado JL, Fridlyand J, Patel H, Jain AN, Busam K, Kageshita T, Ono T, Albertson DG, Pinkel D, Bastian BC (2003) Determinants of BRAF mutations in primary melanomas. J Natl Cancer Inst 95:1878-1890

25. Mudhar HS, Parsons MA, Sisley K, Rundle P, Singh A, Rennie IG (2004) A critical appraisal of the prognostic and predictive factors for uveal malignant melanoma. Histopathology 45:1-12

26. Natali PG, Nicotra MR, Digiesi G, Cavaliere R, Bigotti A, Trizio D, Segatto O (1994) Expression of gp185HER-2 in human cutaneous melanoma: implications for experimental immunotherapeutics. Int J Cancer 56:341-346

27. Parrella P, Caballero OL, Sidransky D, Merbs SL (2001) Detection of c-myc amplification in uveal melanoma by fluorescent in situ hybridization. Invest Ophthalmol Vis Sci 42:1679-1684
28. Pastorino F, Brignole C, Marimpietri D, Pagnan G, Morando A, Ribatti D, Semple SC, Gambini C, Allen TM, Ponzoni M (2003) Targeted liposomal c-myc antisense oligodeoxynucleotides induce apoptosis and inhibit tumor growth and metastases in human melanoma models. Clin Cancer Res 9:4595-4605

29. Pegram MD, Lipton A, Hayes DF, Weber BL, Baselga JM, Tripathy D, Baly D, Baughman SA, Twaddell T, Glaspy JA, Slamon DJ (1998) Phase II study of receptor-enhanced chemosensitivity using recombinant humanized antip185HER2/neu monoclonal antibody plus cisplatin in patients with HER2/neu-overexpressing metastatic breast cancer refractory to chemotherapy treatment. J Clin Oncol 16:2659-2671

30. Persons DL, Arber DA, Sosman JA, Borelli KA, Slovak ML (2000) Amplification and overexpression of HER-2/neu are uncommon in advanced stage melanoma. Anticancer Res 20:1965-1968

31. Potti A, Hille RC, Koch M (2003) Immunohistochemical determination of HER-2/neu overexpression in malignant melanoma reveals no prognostic value, while c-Kit (CD117) overexpression exhibits potential therapeutic implications. J Carcinog 2:8

32. Ragnarsson-Olding B, Platz A, Olding L, Ringborg U (2004) p53 protein expression and TP53 mutations in malignant melanomas of sun-sheltered mucosal membranes versus chronically sun-exposed skin. Melanoma Res 14:395-401

33. Sasaki Y, Niu C, Makino R, Kudo C, Sun C, Watanabe H, Matsunaga J, Takahashi K, Tagami H, Aiba S, Horii A (2004) BRAF point mutations in primary melanoma show different prevalences by subtype. J Invest Dermatol 123:177-183

34. Sauter ER, Yeo UC, von Stemm A, Zhu W, Litwin S, Tichansky DS, Pistritto G, Nesbit M, Pinkel D, Herlyn M, Bastian BC (2002) Cyclin D1 is a candidate oncogene in cutaneous melanoma. Cancer Res 62:3200-3206

35. Shinozaki H, Ozawa S, Ando N, Tsuruta H, Terada M, Ueda M, Kitajima M (1996) Cyclin D1 amplification as a new predictive classification for squamous cell carcinoma of the esophagus, adding gene information. Clin Cancer Res 2:1155-1161

36. Simon R, Mirlacher M, Sauter G (2004) Tissue microarrays. Methods Mol Med 97:377-389

37. Singh AD, Boghosian-Sell L, Wary KK, Shields CL, De Potter P, Donoso LA, Shields JA, Cannizzaro LA (1994) Cytogenetic findings in primary uveal melanoma. Cancer Genet Cytogenet $72: 109-115$

38. Sisley K, Cottam DW, Rennie IG, Parsons MA, Potter AM, Potter CW, Rees RC (1992) Non-random abnormalities of chromosomes 3, 6, and 8 associated with posterior uveal melanoma. Genes Chromosomes Cancer 5:197-200

39. Sisley K, Rennie IG, Parsons MA, Jacques R, Hammond DW, Bell SM, Potter AM, Rees RC (1997) Abnormalities of chromosomes 3 and 8 in posterior uveal melanoma correlate with prognosis. Genes Chromosomes Cancer 19:22-28

40. Treszl A, Adany R, Rakosy Z, Kardos L, Begany A, Gilde K, Balazs M (2004) Extra copies of c-myc are more pronounced in nodular melanomas than in superficial spreading melanomas as revealed by fluorescence in situ hybridisation. Cytometry B Clin Cytom 60:37-46

41. van Dijk M, Sprenger S, Rombout P, Marres H, Kaanders J, Jeuken J, Ruiter D (2003) Distinct chromosomal aberrations in sinonasal mucosal melanoma as detected by comparative genomic hybridization. Genes Chromosomes Cancer 36: $151-158$

42. White VA, Chambers JD, Courtright PD, Chang WY, Horsman DE (1998) Correlation of cytogenetic abnormalities with the outcome of patients with uveal melanoma. Cancer 83:354-359 